\title{
Androgen receptor phosphorylation at serine 515 by Cdk1 predicts biochemical relapse in prostate cancer patients
}

\author{
J M Willder ${ }^{1,2,6}$, S J Heng ${ }^{1,6}$, P McCall ${ }^{1}$, C E Adams ${ }^{1}$, C Tannahill ${ }^{1}$, G Fyffe ${ }^{1}$, M Seywright ${ }^{3}$, P G Horgan ${ }^{2}$, \\ H Y Leung ${ }^{1,4,5}$, M A Underwood ${ }^{5}$ and J Edwards*,1 \\ ${ }^{1}$ Institute of Cancer, University of Glasgow, McGregor Building, Western Infirmary, Glasgow G11 6NT, UK; ${ }^{2}$ Academic Department \\ of Surgery, School of Medicine, University of Glasgow, Walton Building, Glasgow Royal Infirmary, 84 Castle Street, Glasgow, \\ G4 OSF, UK; ${ }^{3}$ Department of Pathology, McGregor Building, Western Infirmary, Glasgow G11 6NT, UK; ${ }^{4}$ Beatson Institute of \\ Cancer Research, Switchback Road, Glasgow G61 1BD, UK and ${ }^{5}$ Department of Urology, Southern General Hospital, Glasgow \\ G31 2ER, UK
}

Background: Prostate cancer cell growth is dependent upon androgen receptor (AR) activation, which is regulated by specific kinases. The aim of the current study is to establish if AR phosphorylation by Cdk1 or ERK1/2 is of prognostic significance.

Methods: Scansite 2.0 was utilised to predict which AR sites are phosphorylated by Cdk1 and ERK1/2. Immunohistochemistry for these sites was then performed on 90 hormone-naive prostate cancer specimens. The interaction between Cdk1/ERK1/2 and AR phosphorylation was investigated in vitro using LNCaP cells.

Results: Phosphorylation of AR at serine $515\left(\mathrm{pAR}^{5515}\right)$ and PSA at diagnosis were independently associated with decreased time to biochemical relapse. Cdk1 and pCdk $1^{161}$, but not ERK1/2, correlated with $p A R^{S 515}$. High expression of $p A R^{5515}$ in patients with a PSA at diagnosis of $\leqslant 20 \mathrm{ng} \mathrm{ml}^{-1}$ was associated with shorter time to biochemical relapse $(P=0.019)$. This translated into a reduction in disease-specific survival (10-year survival, $38.1 \%$ vs $100 \%, P<0.001)$. In vitro studies demonstrated that treatment with Roscovitine (a Cdk inhibitor) caused a reduction in $\mathrm{pCdk} 1^{161}$ expression, $\mathrm{pAR}{ }^{\mathrm{S515}}$ expression and cellular proliferation.

Conclusion: In prostate cancer patients with PSA at diagnosis of $\leqslant 20 \mathrm{ng} \mathrm{ml}^{-1}$, phosphorylation of AR at serine 515 by Cdk1 may be an independent prognostic marker.

An estimated 899000 men were diagnosed with prostate cancer worldwide in 2008 with most cases in developed countries (Ferlay et al, 2010). Incidence is increasing and expected to rise $69 \%$ by 2030 in the United Kingdom (Mistry et al, 2011). Prostate cancer therefore represents a considerable economic burden. Treatment decision-making in prostate cancer is increasing in complexity, but in general patients with PSA $<20 \mathrm{ng} \mathrm{ml}^{-1}$ at diagnosis are offered immediate or delayed radical treatment dependent on life expectancy, biopsy result and imaging. However, not all patients harbour disease that requires treatment. Conversely, some patients undergo treatment delay following a period of surveillance creating an opportunity for occult aggressive disease to progress. Currently, there are no reliable diagnostic tools to differentiate indolent from aggressive cancers. This results in both over- and under-treatment problems with consequent patient-related morbidity and mortality and substantial economic cost.

The molecular mechanisms underlying the natural history of prostate cancer remain elusive. However, it is accepted that prostate cancer cell growth and survival are exquisitely dependent upon activation of the androgen receptor (AR) by androgens.

${ }^{*}$ Correspondence: Dr J Edwards; E-mail: joanne.edwards@glasgow.ac.uk
${ }^{6}$ Willder and Heng are joint first authors.

Received 11 June 2012; revised 30 August 2012; accepted 27 September 2012; published online 4 December 2012

(c) 2013 Cancer Research UK. All rights reserved 0007-0920/13 
Following ligand binding, AR undergoes further phosphorylation at serine residues (Kuiper and Brinkmann, 1995; Gioeli and Paschal, 2012). Such phosphorylation is thought to inhibit proteolytic degradation and stabilise AR homodimers (Blok et al, 1998). Phosphorylation of AR may also influence transactivation of the AR since AR transcriptional activity correlates strongly with phosphorylation of specific serine residues (Blok et al, 1998). Phosphorylation may be seen as a mechanism that generates changes within the specific domains that affect AR function. Although each of the major AR domains contains at least one phosphorylation site, the majority are located in the N-terminal domain (NTD), which is important for AR transactivation, including Ser-81, Ser-94, Ser-308 and Ser-515 (Gioeli and Paschal, 2012). In addition, Ser-650 is located in the hinge region, which regulates nuclear localisation, DNA binding and co-activator recruitment (Zhou et al, 1995; Gioeli et al, 2006; Gioeli and Paschal, 2012). Androgen receptor Ser-515 phosphorylation in particular has been linked to nuclear-cytoplasmic shuttling (Ponguta et al, 2008), while Ser-81 phosphorylation has been shown to mediate chromatin binding and transcriptional activation (Chen et al, 2012). It is therefore plausible that alterations in AR phosphorylation may drive prostate carcinogenesis. However, few studies have explored the significance of AR phosphorylation in prostate cancer in the clinical setting.

Several kinases have been associated with established AR phosphorylation (Zhou et al, 1995; Wong et al, 2004; Gioeli and Paschal, 2012). In particular, cyclin-dependent kinase 1 (Cdk1) and the mitogen-activated protein kinases also known as extracellular signal regulated kinase 1 and 2 (ERK1/2) have been associated with AR phosphorylation at various serine sites (Chen et al, 2006; Shigemura et al, 2009; Gioeli and Paschal, 2012). However, conflicting data exists over the responsible kinase(s) and functional consequences of phosphorylation at each site. Upregulation of the ERK1/2 pathway has been associated with development of castrateresistant prostate cancer and reduced disease-specific survival (Mukherjee et al, 2011). ERK1/2-induced phosphorylation of the $\mathrm{AR}$ at serine 515 has been demonstrated to hyper-sensitise LNCaP cells to low levels of synthetic androgens, increase AR transactivation, facilitate recruitment of $\mathrm{AR}$ cofactors and increase prostate cancer cell growth (Bakin et al, 2003). Cdk1 is reported to be upregulated in prostate cancer tissue (Kallakury et al, 1997) and phosphorylation of $\mathrm{AR}$ at serine 81 in vitro by Cdk1 is associated with prevention of AR degradation, thereby increasing AR stability and resulting in increased AR protein expression (Chen et al, 2006). However, cell line studies that investigated mutagenesis at serine 81 indicate that phosphorylation at this site alone does not drive AR transcriptional activity or stabilisation, suggesting that Cdk1 may mediate these effects on the AR through phosphorylation at multiple sites (Zhou et al, 1995; Chen et al, 2006; Gioeli et al, 2006).

In the current study, we aim to determine whether AR phosphorylation at $\mathrm{Cdk} 1$ and ERK1/2 consensus sites is associated with clinico-pathologic parameters and outcome in a cohort of hormone-naive prostate cancer patients. It is hypothesised that AR phosphorylation at certain sites may be associated with disease progression and the knowledge of such may help to inform treatment decision-making.

\section{MATERIALS AND METHODS}

Patients. Ninety patients with hormone-naive prostate cancer samples available were recruited at the Glasgow Royal Infirmary between 1992 and 2002. Last date of follow-up was 11/01/2012. Patients gave written consent. Clinical data included age, Gleason score, tumour lymphovascular invasion (LVI), serum PSA levels at diagnosis, biochemical recurrence, serum PSA at biochemical recurrence and presence of metastases. Patients were considered to have biochemical recurrence dependent on treatment; radical prostatectomy serum PSA $>0.2 \mathrm{ng} \mathrm{ml}^{-1}$, radical radiotherapy serum PSA of $2.0 \mathrm{ng} \mathrm{ml}^{-1}$ above the post-treatment nadir level, hormone treatment 2-3 consecutive rises in serum PSA levels above the nadir obtained at intervals of $>2$ weeks (Roach et al, 2006; Cookson et al, 2007). Study end points were biochemical relapse, survival from biochemical relapse and disease-specific survival. West of Scotland Research Ethics Committee approved the study (reference: 05/S0704/94).

Identification of kinases mediating AR phosphorylation. Scansite 2.0 was utilised to predict which sites on the AR would be phosphorylated by Cdk1 and ERK1/2 (Obenauer et al, 2003). The search was conducted using the protein ID 'ANDR_HUMAN' (accession number: P10275).

Tissue microarray construction. Three $0.6 \mathrm{~mm}^{2}$ cores of prostate cancer tissue, identified by a uropathologist, were removed from formalin-fixed paraffin-embedded blocks. Recipient array blocks were constructed in triplicate. Control cores of normal prostate, colon, breast, pancreas, tonsil, kidney, liver and lung tissue were included in each tissue microarray (TMA).

Immunohistochemistry. Immunohistochemistry (IHC) was conducted in triplicate on aforementioned TMAs for the following proteins: Cdk1, Cdk1 activated through Thr-161 (pCdk1 ${ }^{161}$ ) phosphorylation, ERK1/2 activated through Thr-202 and Tyr-204 $\left(\mathrm{pERK} 1^{202 / 204}\right)$ or Thr-185 and Tyr-187 (pERK2 ${ }^{185 / 187}$ ) phosphorylation, Ki67 (proliferation index), AR and AR phosphorylated at Ser-81 $\left(\mathrm{pAR}^{\mathrm{S} 81}\right)$, Ser-94 (pAR $\left.{ }^{\mathrm{S} 94}\right)$, Ser-308 $\left(\mathrm{pAR}^{\mathrm{S308}}\right)$, Ser-515 $\left(\mathrm{pAR}^{\mathrm{S} 515}\right)$ and Ser-650 $\left(\mathrm{pAR}^{\mathrm{S} 650}\right)$. Tissue microarrays were dewaxed in xylene and rehydrated through graded alcohol. The AR antigen retrieval was performed in DakoCytomation Target Retrieval Solution (Dako UK Ltd., Ely, UK) pre-heated water bath, $99^{\circ} \mathrm{C}, 20 \mathrm{~min}$. pERK1/2 antigen retrieval was performed in $\mathrm{pH} 9$ Tris-EDTA buffer (10 mM Trizma Base, $0.25 \mathrm{mM}$ EDTA), $96^{\circ} \mathrm{C}$, 20 min. Ki67 antigen retrieval was performed using heat treatment

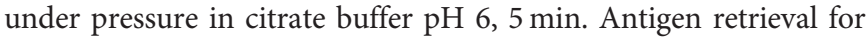
remaining proteins was performed using heat treatment under pressure in Tris-EDTA buffer ( $5 \mathrm{mM}$ Trizma Base, $1 \mathrm{mM}$ EDTA, $\mathrm{pH} 8$ ), $5 \mathrm{~min}$. Sections cooled in buffer for $20 \mathrm{~min}$ before washing in $3 \% \mathrm{H}_{2} \mathrm{O}_{2}$. Sections blocked using $5 \%$ horse serum (10\% casein for pERK1/2) in Tris-buffered saline (TBS). Antibodies for Cdk1 (\#ab18; Abcam, Cambridge, UK), pAR ${ }^{\mathrm{S} 308}$ (\#sc-26406-R; Santa Cruz Biotechnology Inc., Santa Cruz, CA, USA) and Ki67 (\#F0788; Dako UK Ltd.) were incubated for $1 \mathrm{~h}, 25^{\circ} \mathrm{C}$ diluted at $1: 200,1: 75$ and $1: 150$, respectively. Antibodies for $\mathrm{pCdk}^{161}$ (\#ab47329; Abcam), pERK1/2 (pERK1 ${ }^{202 / 204}$, pERK2 $\left.{ }^{185 / 187}\right)$ (\#9101; Cell Signaling Technology Inc., Danvers, MA, USA), AR (\#M3562; Dako UK Ltd.), pAR ${ }^{S 81}$ (\#07-1375; Merk Millipore, Billerica, MA, USA), pAR ${ }^{\mathrm{S} 94}$ (\#ab62205; Abcam), $\mathrm{pAR}^{\mathrm{S} 515}$ (Protein sequence MVSRVPYP-S(PO3H2)-PTCV, raised in rabbit by Eurogentec Ltd., Southampton, UK) and $\mathrm{pAR}^{\mathrm{S} 650}$ (\#ab47563-100; Abcam) were incubated overnight at $4{ }^{\circ} \mathrm{C}$ diluted at $1: 50,1: 100,1: 100$, $1: 1000,1: 25,1: 500$ and $1: 100$, respectively. All antibodies diluted in Dako antibody diluent (Dako UK Ltd.). Bound antibody complex visualised using EnVision plus kit (\#K5007; Dako UK Ltd.) followed by 3,3-diaminobenzidine tetrahydrochloride (DAB, Dako UK Ltd.). Nuclei were counterstained with haematoxylin and Scots Tap Water Substitute, dehydrated through graded alcohol and xylene and mounted with Di-N-Butyl Phthalate in xylene.

Antibody validation. Peptide competition assays were performed to confirm antibody specificity for each AR serine phosphorylation site. pAR ${ }^{\mathrm{S} 08}$ (\#sc-26406-P; Santa Cruz Biotechnology Inc.) peptide was incubated at a ratio of $3: 1$ for $1 \mathrm{~h}$ with each antibody. $\mathrm{pAR}^{881}$ (Protein sequence QQQQQQET(pS)PRQQ raised in rabbit by 
EZbiolab Inc., Carmel, IN, USA), $\mathrm{pAR}^{\mathrm{S} 94}$ (Protein sequence QQQQQGEDG(pS)PQAH raised in rabbit by EZbiolab Inc.), $\mathrm{pAR}^{\mathrm{S} 515}$ (Protein sequence MVSRVPYP-S(pS)-PTCV raised in rabbit by Eurogentec Ltd.) and $\mathrm{pAR}^{\mathrm{S} 650}$ (Protein sequence EEGEASSTT(pS)PTEE raised in rabbit by EZbiolab Inc.) peptides were incubated at ratios of $1: 1,2: 1,500: 1$ and $100: 1$, respectively, with each antibody overnight at $4{ }^{\circ} \mathrm{C}$. Immunohistochemistry was then performed as described above and results are shown in Supplementary data.

Scoring. Tissue staining intensity was scored by two blinded independent observers using a weighted histo-score (H-score) method (McCarty et al, 1986; Kirkegaard et al, 2006). H-score was calculated from the formula: $(0 \times \%$ cells staining negative $)+(1$ $\times \%$ cells staining weakly positive $)+(2 \times \%$ cells staining moderately positive $)+(3 \times \%$ cells staining strongly positive $)$. The mean $\mathrm{H}$-score from staining conducted in triplicate was used for analysis.

Western blotting. Cells were lysed in radioimmunoprecipitation assay buffer and Roche protease inhibitor cocktail set one. Lysates were centrifuged at 14000 r.p.m. for $15 \mathrm{~min}$ at $4{ }^{\circ} \mathrm{C}$, supernatant removed and protein concentration determined using Bradford's assay (Bio-Rad Laboratories Ltd., Hemel Hempstead, UK). In all, $50 \mu \mathrm{g}$ of protein per well was resolved by $10 \%$ SDS-PAGE and transferred onto PVDF membranes (Bio-Rad Laboratories Ltd.). Membranes were blocked for $1 \mathrm{~h}$ in $5 \%$ non-fat milk in TTBS $(1 \times$ TBS and $0.1 \%$ Tween-20) and probed with primary antibodies at $4{ }^{\circ} \mathrm{C}$ overnight. Membranes were incubated with secondary antibodies (Cell Signaling Technology, Inc.) and visualised with ECL plus kit (Fisher Scientific UK Ltd., Loughborough, UK). Membranes were stripped by incubating with Re-Blot Plus stripping buffer (Merk Millipore) then incubated with ECL plus kit to ensure complete stripping. The membranes were then blocked for $1 \mathrm{~h}$ in 5\% non-fat milk in TTBS $(1 \times$ TBS and $0.1 \%$ Tween-20) and probed with anti-Tubulin (Abcam) to confirm equal protein loading.

Cdk1 inhibition. Inhibitor studies were conducted to determine whether endogenous Cdk1 mediates AR phosphorylation in prostate cancer cells. LNCaP cells were treated with Roscovitine $(20 \mu \mathrm{M})$, a selective inhibitor of cellular Cdks (Cdk1, Cdk2 and Cdk5) for $24 \mathrm{~h}$ or dihydrotestosterone (DHT) (10 nM) for $3 \mathrm{~h}$. Cells were trypsinised and collected by centrifugation at 1200 r.p.m. The supernatant was discarded and pellets were washed in HBSS. Cells were fixed in $4 \%$ formalin, briefly vortexed and rested at room temperature for $15 \mathrm{~min}$. Cells were then centrifuged at 2500 r.p.m. for $3 \mathrm{~min}$, the supernatant discarded and then washed in HBSS. Cells were set in $1 \%$ agarose at $4{ }^{\circ} \mathrm{C}$ for $1 \mathrm{~h}$. Cell pellets were dehydrated through graded alcohol and xylene and embedded into paraffin blocks. Immunohistochemistry was performed as described (antigen retrieval reduced to $2.5 \mathrm{~min}$ ) for protein expression of $\mathrm{pCdk}^{161}, \mathrm{pAR}^{\mathrm{S} 81}, \mathrm{pAR}^{\mathrm{S} 515}$ and Ki67.

Statistical analysis. Statistical analysis was performed using SPSS version 19.0 for Windows (IBM, Armonk, NY, USA). Intra-class correlation coefficients (ICCCs) confirmed histo-scoring consistency between observers. Pearson's rank correlation coefficients (CC) assessed associations between protein expression. MannWhitney $U$-test or Kruskal-Wallis test assessed relationships between protein expression and clinico-pathologic characteristics. Kaplan-Meier methods, using the log-rank test, compared survival between patients according to clinico-pathologic parameters and high/low protein expression. Significant univariate results were included in a backwards conditional cox-regression model to determine independence from current clinical parameters. A $<0.05$ significance level was used and Bonferroni correction was used where applicable.

\section{RESULTS}

Patient characteristics. Analysis was based on 90 hormone-naive prostate cancer patients. Patient characteristics are shown in Table 1. Twenty-three patients had metastases to local lymph nodes (3), bone (13) and at both sites (7).

Forty-seven patients had biochemical relapse (median time to biochemical relapse 2.7 years, interquartile range 1.5-3.8). Twentyfour patients were alive at the time of analysis, median follow-up was 11.7 years (interquartile range 9.9-14.0). Forty-six died of their disease (median time to death 4 years, interquartile range 1.9-7.2) and twenty deaths were attributed to intercurrent disease (median time to death $4.1 \mathrm{yr}$, interquartile range 0.9-5.5). Table 2 shows associations with clinical parameters (grouped data) and outcome measures using Kaplan-Meier methods.

Protein expression analysis. Expression of all proteins was observed at varying levels in the cytoplasm and nucleus of both stromal and epithelial cells (Figure 1). Protein expression was found to be heterogeneous throughout and less intense in the stromal cells. There was presence of PIN and benign tissue, adjacent to the neoplastic tissue, in some of the TMA cores. Expression of proteins in the interspersed PIN and benign tissue and the normal prostate control core was heterogeneous and less intense than the neoplastic tissue. Only protein expression observed in the tumour cells was scored. All ICCC values were $>0.80$. Protein expression levels were subdivided into low $(\leqslant$ median $)$ and high expression ( $>$ median) for analysis.

Association between protein expression and clinico-pathologic outcome measures

$A R$ and $A R$ phosphorylated at serine residues. High expression of $\mathrm{pAR}^{\mathrm{S} 81}$ (cytoplasmic), $\mathrm{pAR}^{\mathrm{S} 515}$ (nuclear and total) and $\mathrm{pAR}^{\mathrm{S} 650}$ (cytoplasmic, nuclear and total) was associated with increased age (Table 3A). High expression of nuclear $\mathrm{pAR}^{\mathrm{S} 308}$ was associated

\begin{tabular}{|c|c|}
\hline Clinical parameter & Percentage of patients (\%) \\
\hline \multicolumn{2}{|l|}{ Age (years) } \\
\hline $\begin{array}{l}<70 \\
\geqslant 70\end{array}$ & $\begin{array}{l}37.8 \\
62.2\end{array}$ \\
\hline \multicolumn{2}{|l|}{ Gleason } \\
\hline $\begin{array}{l}<7 \\
=7 \\
>7\end{array}$ & $\begin{array}{l}31.2 \\
32.5 \\
36.4\end{array}$ \\
\hline \multicolumn{2}{|l|}{ PSA at diagnosis } \\
\hline $\begin{array}{l}<10 \mathrm{ng} \mathrm{ml}^{-1} \\
10-20 \mathrm{ng} \mathrm{ml}^{-1} \\
>20 \mathrm{ng} \mathrm{ml}^{-1}\end{array}$ & $\begin{array}{l}27.5 \\
20.3 \\
52.2\end{array}$ \\
\hline \multicolumn{2}{|c|}{ Lymphovascular invasion } \\
\hline $\begin{array}{l}\text { Absence } \\
\text { Presence }\end{array}$ & $\begin{array}{r}93.3 \\
6.7\end{array}$ \\
\hline \multicolumn{2}{|l|}{ Recurrence PSA } \\
\hline $\begin{array}{l}<10 \mathrm{ng} \mathrm{ml}^{-1} \\
10-20 \mathrm{ng} \mathrm{ml}^{-1} \\
>20 \mathrm{ng} \mathrm{ml}^{-1}\end{array}$ & $\begin{array}{r}77.6 \\
2.0 \\
20.4\end{array}$ \\
\hline
\end{tabular}


Table 2. Relationship between clinical parameters and clinical outcome measures

\begin{tabular}{|c|c|c|c|}
\hline & $\begin{array}{c}\text { Time to } \\
\text { biochemical relapse }\end{array}$ & $\begin{array}{l}\text { Survival from } \\
\text { biochemical relapse }\end{array}$ & $\begin{array}{c}\text { Disease-specific } \\
\text { survival }\end{array}$ \\
\hline Age ( $<70$ vs $\geqslant 70$ years) & 0.260 & 0.385 & 0.020 \\
\hline Gleason $(<7$ vs $=7$ vs $>7)$ & 0.013 & 0.754 & 0.008 \\
\hline Diagnosis PSA ( $<10$ vs $10-20$ vs $>20 \mathrm{ng} \mathrm{ml}^{-1}$ ) & 0.002 & 0.078 & 0.001 \\
\hline Recurrence PSA ( $<10$ vs $10-20$ vs $>20 \mathrm{ng} \mathrm{ml}^{-1}$ ) & & $<0.001$ & $<0.001$ \\
\hline Lymphovascular invasion (presence vs absence) & 0.001 & 0.612 & 0.114 \\
\hline Presence of metastases (presence vs absence) & 0.001 & 0.008 & $<0.001$ \\
\hline Ki67 ( $\leqslant$ median vs $>$ median) & 0.730 & 0.279 & 0.033 \\
\hline \multicolumn{4}{|c|}{$\begin{array}{l}\text { Abbreviation: PSA }=\text { prostate specific antigen. } \\
\text { The clinical variables were grouped and analysed by Kaplan-Meier methods with reference to clinical outcome measures as shown. } \\
\text { Patients were considered to have biochemical relapse dependent on treatment; radical prostatectomy serum PSA }>0.2 \mathrm{ng} \mathrm{ml}^{-1} \text {, radical radiotherapy serum PSA of } 2.0 \mathrm{ng} \mathrm{ml}^{-1} \text { above the post- } \\
\text { treatment nadir level, hormone treatment } 2-3 \text { consecutive rises in serum PSA levels above the nadir obtained at intervals of }>2 \text { weeks (Roach et al, 2006; Cookson et al, 2007). } \\
\text { Numbers in bold denote significant associations with } P \text {-value }<0.05 \text {. }\end{array}$} \\
\hline
\end{tabular}
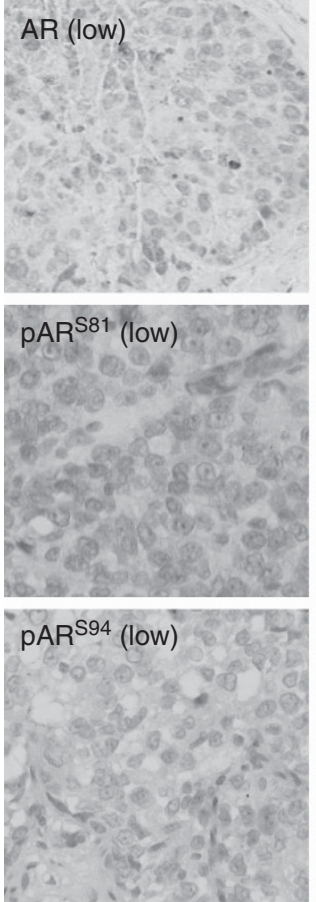
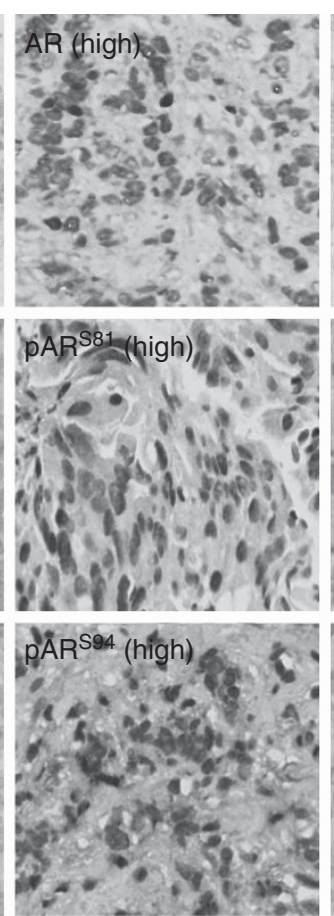
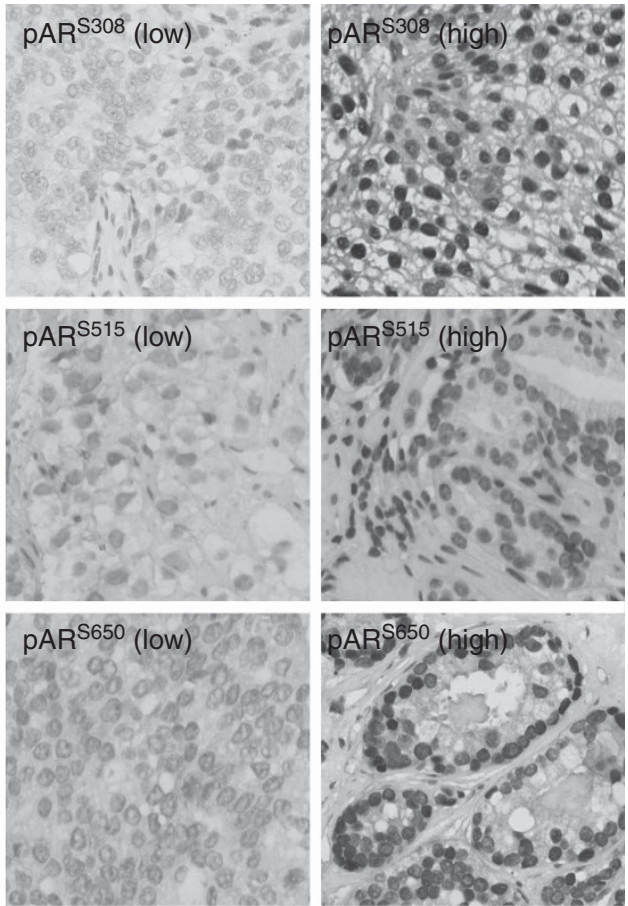

Figure 1. Image illustrating high ( $>$ median histoscore) and low ( $\leqslant$ median histoscore) intensity immunohistochemical staining for androgen receptor (AR) and $A R$ phosphorylated at Ser-81 $\left(p A R^{S 81}\right), 94\left(p A R^{S 94}\right), 308\left(p A R^{S 308}\right), 515\left(p A R^{S 515}\right)$ and $650\left(p A R^{S 650}\right)(\times 10$ magnification). Intra-class correlation coefficients (ICCCS) confirmed histoscoring consistency between two independent observers and all ICCC values were $>0.80$.

with increased PSA level at diagnosis. Presence of LVI was associated with high AR (nuclear, cytoplasmic and total) and $\mathrm{pAR}^{\mathrm{S} 515}$ (cytoplasmic) expression. Presence of metastases was associated with high $\mathrm{AR}$ (total) and $\mathrm{pAR}^{\mathrm{S} 515}$ (cytoplasmic) expression. High expression of $\mathrm{pAR}^{\mathrm{S} 81}$ (nuclear and total) and low expression of $\mathrm{pAR}^{\mathrm{S} 94}$ (cytoplasmic) were associated with high Ki67 score (>median) (Table $3 \mathrm{~A})$.

Candidate kinases. High total $\mathrm{pCdk} 1^{161}$ expression was associated with increased age (Table $3 \mathrm{~B}$ ). High expression of $\mathrm{pCdk} 1^{161}$ (nuclear and total) was associated with increased PSA level at relapse. Conversely, high nuclear pERK1/2 expression was associated with low Ki67 score ( $\leqslant$ median) (Table 3B).

Kinases mediating AR phosphorylation. Scansite 2.0 predicted Cdk1 and ERK1/2 as strong candidates mediating phosphorylation of Ser-81, Ser-94, Ser-308, Ser-515 and Ser-650. In the clinical specimens, pERK1/2 expression was not associated with any of the candidate AR phosphorylation sites; however, Cdk1 and pCdk $1^{161}$ were significantly associated with $\mathrm{pAR}^{\mathrm{S81}}$ and $\mathrm{pAR}^{\mathrm{S515}}$ (Table 4).

Associations observed between protein expression and time to biochemical relapse. No associations were observed between the kinases and time to biochemical relapse; however, high nuclear AR was associated with biochemical relapse (proportion of patients relapsed at 5 years $79.2 \%$ vs $46.9 \%$ ) HR 2.8 (95\% CI $1.5-5.3$ ), $P=0.001$, as was high total AR (proportion of patients relapsed at 5 years $85.1 \%$ vs $40.2 \%$ ) HR 3.03 (95\% CI 1.6-5.6), $P<0.001$. High cytoplasmic $\mathrm{pAR}^{\mathrm{S} 515}$ was also associated with biochemical relapse (proportion of patients relapsed at 5 years $78.6 \%$ vs 56\%) HR 2.15 (95\% CI 1.1-4.2), $P=0.02$ (Table 5). 
Table 3. (A) Associations between clinical variables and androgen receptor phosphorylation sites. (B) Associations between clinical variables and candidate kinases

\section{Clinical variables}

\begin{tabular}{|c|c|c|c|c|c|c|c|}
\hline Proteins & $\begin{array}{c}\text { Age } \\
(<70 \text { vs } \\
\geqslant 70 \text { years })\end{array}$ & $\begin{array}{c}\text { Gleason } \\
(<7 \text { vs }=7 \\
\text { vs }>7)\end{array}$ & $\begin{array}{l}\text { Diagnosis PSA } \\
(<10 \text { vs } 10-20 \\
\text { vs }>20 \mathrm{ng} \mathrm{ml}^{-1}\end{array}$ & $\begin{array}{l}\text { Recurrence PSA } \\
\left(<10 \text { vs } 10-20^{-20}\right. \\
\left.\text { vs }>20 \text { ng ml }^{-1}\right)\end{array}$ & $\begin{array}{c}\text { Lymphovascular } \\
\text { invasion (presence } \\
\text { vs absence) }\end{array}$ & $\begin{array}{c}\text { Presence of } \\
\text { metastases } \\
\text { (presence vs absence) }\end{array}$ & $\begin{array}{c}\text { Ki67 } \\
(\leqslant \text { median } \\
\text { vs }>\text { median })\end{array}$ \\
\hline
\end{tabular}

AR

\begin{tabular}{|l|l|l|l|l|l|l|l|}
\hline Cytoplasm & 0.909 & 0.841 & 0.979 & 0.496 & 0.028 & 0.061 & 0.107 \\
Nucleus & 0.284 & 0.450 & 0.301 & 0.380 & $\mathbf{0 . 0 0 6}$ & 0.154 \\
Total & 0.422 & 0.464 & 0.493 & 0.800 & $\mathbf{0 . 0 0 2}$ & $\mathbf{0 . 0 2 7}$ & 0.627 \\
\hline
\end{tabular}

pAR ${ }^{\mathrm{S} 81}$

\begin{tabular}{|l|l|l|l|l|l|l|l|}
\hline Cytoplasm & $\mathbf{0 . 0 3 5}$ & 0.811 & 0.269 & 0.566 & 0.175 & 0.660 & 0.498 \\
Nucleus & 0.651 & 0.401 & 0.462 & 0.601 & 0.666 & 0.229 & 0.039 \\
Total & 0.220 & 0.425 & 0.389 & 0.632 & 0.290 & 0.04195 \\
\hline
\end{tabular}

$\mathrm{pAR}^{\mathrm{S94}}$

\begin{tabular}{|l|l|l|l|l|l|l|l|}
\hline Cytoplasm & 0.447 & 0.714 & 0.437 & 0.820 & 0.234 & 0.165 & 0.040 \\
Nucleus & 0.651 & 0.069 & 0.726 & 0.386 & 0.234 & 0.892 & 0.361 \\
Total & 0.754 & 0.417 & 0.964 & 0.496 & 0.864 & 0.554 & 0.191 \\
\hline
\end{tabular}

$\mathrm{pAR}^{\mathrm{S308}}$

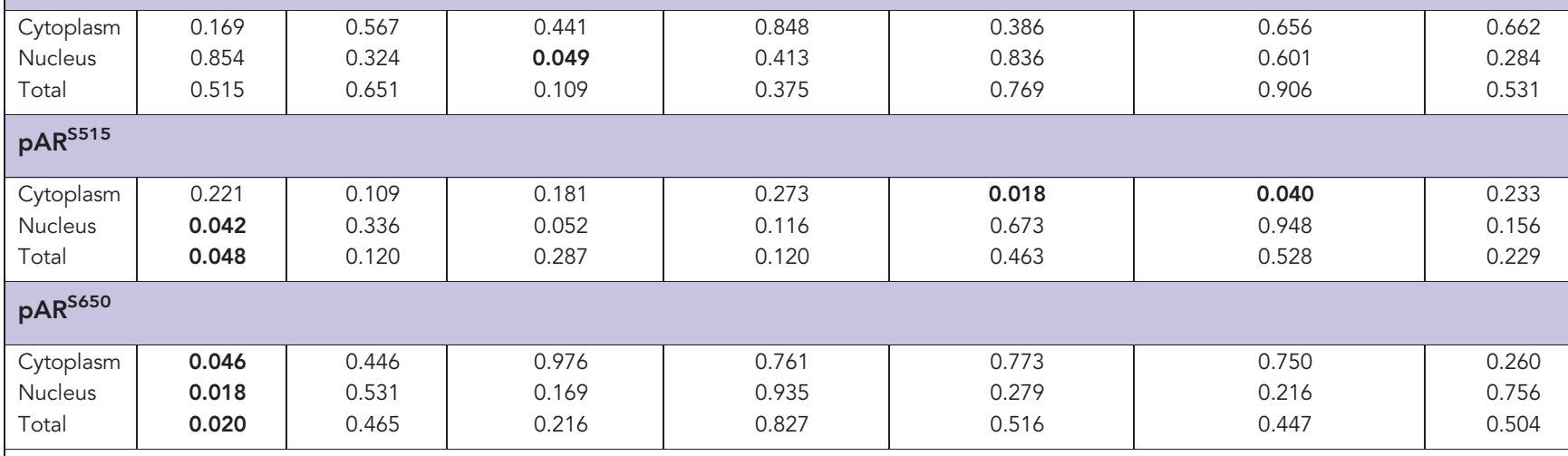

B

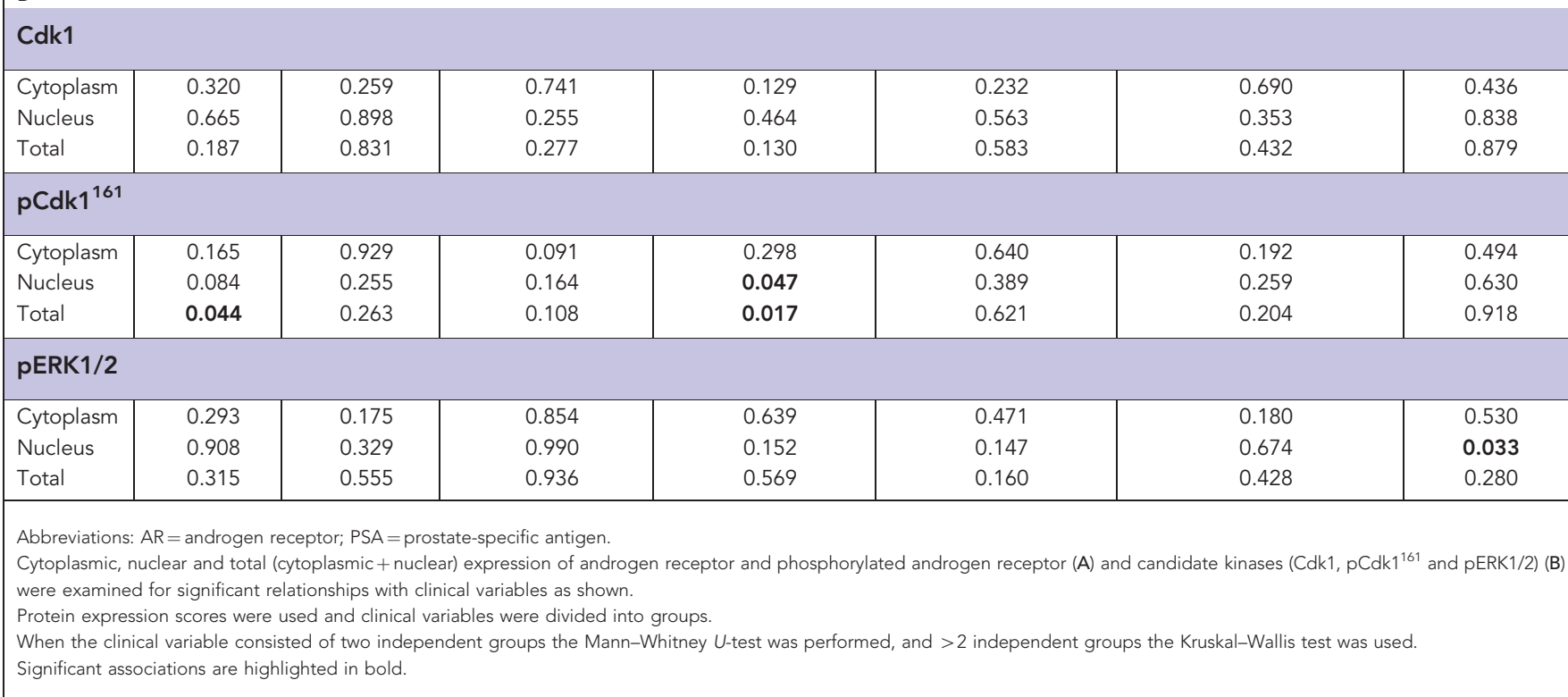


Table 4. Associations between candidate kinases and androgen receptor phosphorylation sites

\begin{tabular}{|c|c|c|c|c|c|c|c|c|c|}
\hline \multirow[b]{3}{*}{ AR phosphorylation sites } & \multicolumn{9}{|c|}{ Candidate kinases } \\
\hline & \multicolumn{3}{|c|}{ Cdk1 } & \multicolumn{3}{|c|}{$\mathrm{pCdk} 1^{161}$} & \multicolumn{3}{|c|}{ pERK1/2 } \\
\hline & Cytoplasmic & Nuclear & Total & Cytoplasmic & Nuclear & Total & Cytoplasmic & Nuclear & Total \\
\hline \multicolumn{10}{|l|}{ Ser-81 } \\
\hline \multicolumn{10}{|l|}{ Cytoplasmic } \\
\hline $\begin{array}{l}C C \\
P \text {-value }\end{array}$ & $\begin{array}{c}0.545 \\
<0.001\end{array}$ & $\begin{array}{l}0.208 \\
0.099\end{array}$ & $\begin{array}{c}0.509 \\
<0.001\end{array}$ & $\begin{array}{l}0.446 \\
0.001\end{array}$ & $\begin{array}{l}0.211 \\
0.134\end{array}$ & $\begin{array}{l}0.346 \\
0.012\end{array}$ & $\begin{array}{c}-0.068 \\
0.61\end{array}$ & $\begin{array}{c}-0.158 \\
0.231\end{array}$ & $\begin{array}{l}0.218 \\
0.113\end{array}$ \\
\hline \multicolumn{10}{|l|}{ Nuclear } \\
\hline $\begin{array}{l}\text { CC } \\
P \text {-value }\end{array}$ & $\begin{array}{l}0.057 \\
0.657\end{array}$ & $\begin{array}{c}0.569 \\
<0.001\end{array}$ & $\begin{array}{l}0.439 \\
<0.001\end{array}$ & $\begin{array}{l}0.185 \\
0.190\end{array}$ & $\begin{array}{l}0.278 \\
0.046\end{array}$ & $\begin{array}{l}0.305 \\
0.028\end{array}$ & $\begin{array}{l}0.019 \\
0.886\end{array}$ & $\begin{array}{l}0.003 \\
0.979\end{array}$ & $\begin{array}{l}0.014 \\
0.918\end{array}$ \\
\hline \multicolumn{10}{|l|}{ Total } \\
\hline $\begin{array}{l}\text { CC } \\
P \text {-value } \\
\text { Ser-515 }\end{array}$ & $\begin{array}{l}0.300 \\
0.016\end{array}$ & $\begin{array}{c}0.500 \\
<0.001\end{array}$ & $\begin{array}{c}0.552 \\
<0.001\end{array}$ & $\begin{array}{l}0.345 \\
0.012\end{array}$ & $\begin{array}{l}0.297 \\
0.032\end{array}$ & $\begin{array}{l}0.382 \\
0.005\end{array}$ & $\begin{array}{c}-0.019 \\
0.888\end{array}$ & $\begin{array}{c}-0.072 \\
0.586\end{array}$ & $\begin{array}{l}0.218 \\
0.113\end{array}$ \\
\hline \multicolumn{10}{|l|}{ Cytoplasmic } \\
\hline $\begin{array}{l}C C \\
P \text {-value }\end{array}$ & $\begin{array}{l}0.273 \\
0.025\end{array}$ & $\begin{array}{l}-0.025 \\
0.843\end{array}$ & $\begin{array}{l}0.167 \\
0.178\end{array}$ & $\begin{array}{c}0.455 \\
<0.001\end{array}$ & $\begin{array}{l}0.008 \\
0.954\end{array}$ & $\begin{array}{l}0.172 \\
0.210\end{array}$ & $\begin{array}{l}0.051 \\
0.706\end{array}$ & $\begin{array}{l}0.061 \\
0.649\end{array}$ & $\begin{array}{l}0.074 \\
0.583\end{array}$ \\
\hline \multicolumn{10}{|l|}{ Nuclear } \\
\hline $\begin{array}{l}\mathrm{CC} \\
P \text {-value }\end{array}$ & $\begin{array}{l}0.181 \\
0.143\end{array}$ & $\begin{array}{c}0.532 \\
<0.001\end{array}$ & $\begin{array}{c}0.507 \\
<0.001\end{array}$ & $\begin{array}{l}0.105 \\
0.444\end{array}$ & $\begin{array}{c}0.558 \\
<0.001\end{array}$ & $\begin{array}{c}0.531 \\
<0.001\end{array}$ & $\begin{array}{c}-0.098 \\
0.464\end{array}$ & $\begin{array}{l}0.038 \\
0.780\end{array}$ & $\begin{array}{c}-0.029 \\
0.831\end{array}$ \\
\hline \multicolumn{10}{|l|}{ Total } \\
\hline $\begin{array}{l}\mathrm{CC} \\
P \text {-value }\end{array}$ & $\begin{array}{l}0.275 \\
0.024\end{array}$ & $\begin{array}{c}0.457 \\
<0.001\end{array}$ & $\begin{array}{l}0.167 \\
<0.001\end{array}$ & $\begin{array}{l}0.297 \\
0.028\end{array}$ & $\begin{array}{c}0.500 \\
<0.001\end{array}$ & $\begin{array}{c}0.549 \\
<0.001\end{array}$ & $\begin{array}{c}-0.061 \\
0.648\end{array}$ & $\begin{array}{l}0.060 \\
0.656\end{array}$ & $\begin{array}{l}0.009 \\
0.949\end{array}$ \\
\hline
\end{tabular}

Associations observed between protein expression and survival from biochemical relapse. Survival from biochemical relapse was calculated from biochemical relapse till death or last follow-up using cancer-specific deaths. High cytoplasmic Cdk1 was associated with survival from biochemical relapse (10-year survival $12.1 \%$ vs $48.9 \%$ ) HR 2.9 (95\% CI 1.2-6.3), $P=0.011$. High nuclear pCdk $1^{161}$ was associated with survival from biochemical relapse (10-year survival $29.2 \%$ vs $51.4 \%$ ) HR 3.18 (95\% CI 1.1-9.3), $P=0.026$ (Table 5). High cytoplasmic $\mathrm{pAR}^{\mathrm{S} 515}$ was associated with survival from biochemical relapse (10-year survival $15.6 \%$ vs 55.5\%) HR 2.9 (95\% CI 1.2-7.1), $P=0.016$ (Table 5).

Associations observed between biomarkers and disease-specific survival. Disease-specific survival was calculated from diagnosis till death or last follow-up using cancer-specific deaths. High cytoplasmic Cdk1 was associated with disease-specific survival (10year survival $26.8 \%$ vs $57.2 \%$ ) HR 2.4 (95\% CI 1.2-4.5), $P=0.007$. High cytoplasmic pCdk1 ${ }^{161}$ was associated with disease-specific survival (10-year survival $29.8 \%$ vs $58.3 \%$ ) HR 2.5 (95\% CI $2.5-$ $5.4), P=0.013$. High nuclear pCdk $1^{161}$ was associated with diseasespecific survival (10-year survival $27.8 \%$ vs $67.9 \%$ ) HR 3.7 (95\% CI 1.6-8.5), $P=0.001$ (Table 5). High total $\mathrm{pCdk} 1{ }^{161}$ was associated with disease-specific survival (10-year survival $30.6 \%$ vs $64.4 \%$ ) HR 2.9 (95\% CI 1.3-6.4), $P=0.007$. High nuclear $\mathrm{pAR}^{\mathrm{S} 81}$ was associated with disease-specific survival (10-year survival $24.4 \%$ vs $54.5 \%$ ), HR 2.112 (95\% CI 1.1-4.2), $P=0.031$. High total $\mathrm{pAR}^{\mathrm{S} 81}$ was associated with disease-specific survival (10-year survival $25.6 \%$ vs 56.5\%), HR 2.0 (95\% CI 1.0-4.1), $P=0.039$. High cytoplasmic $\mathrm{pAR}^{\mathrm{S} 515}$ was associated with disease-specific survival (10-year survival $14.4 \%$ vs $65.2 \%$ ) HR 4.4 (95\%CI 2.1-9.1), $P=1.54 \times 10^{-5}$ (Table 5). High total $\mathrm{pAR}^{\mathrm{S} 515}$ was associated with disease-specific survival (10-year survival $35.8 \%$ vs $57.5 \%$ ), HR 2.1 (95\% CI 1.0-4.2), $P=0.034$.

Multivariate cox-regression analysis to determine if biomarkers are able to independently predict time to biochemical relapse. Expression of $\mathrm{AR}$ and $\mathrm{pAR}^{\mathrm{S515}}$ was combined with Gleason score, PSA at diagnosis, LVI and presence of metastases in multivariate analysis. Cytoplasmic pAR ${ }^{\mathrm{S} 515}$ expression $(P=0.038, \mathrm{HR} 4.5(95 \%$ CI 1.1-20.6) $)$ and PSA at diagnosis $(P=0.003$, HR 7.3 (95\% CI 2.0-27.5)) were independently associated with time to biochemical relapse. As these variables were deemed independent, we investigated whether $\mathrm{pAR}^{\mathrm{S} 515}$ expression could inform on patients with PSA $\leqslant 20 \mathrm{ng} \mathrm{ml}^{-1}$ at diagnosis. These patients, within each individual clinical context, are considered as suitable for immediate or delayed radical treatment (via active surveillance). Many of these patients will have indolent disease that may never reach clinical consequence and therefore are at risk of over-treatment. In contrast, a subset have occult aggressive tumours that will progress if treatment is delayed. Therefore, biomarkers to aid treatment decision-making in this group of patients would have important clinical implications. When patients with PSA at diagnosis $\leqslant 20 \mathrm{ng} \mathrm{ml}^{-1}$ were stratified by cytoplasmic $\mathrm{pAR}^{\mathrm{S} 515}$ expression, those tumours with high expression had significantly shorter time to biochemical relapse than those patients with low expression $(P=0.019)$ (Figure 2A). This translated into significantly shorter 


\begin{tabular}{|c|c|c|c|}
\hline & $\begin{array}{l}\text { Time to } \\
\text { biochemical } \\
\text { relapse }\end{array}$ & $\begin{array}{l}\text { Survival from } \\
\text { biochemical } \\
\text { relapse }\end{array}$ & $\begin{array}{l}\text { Disease- } \\
\text { specific } \\
\text { survival }\end{array}$ \\
\hline AR cytoplasm & 0.466 & 0.922 & 0.517 \\
\hline AR nucleus & 0.001 & 0.688 & 0.233 \\
\hline AR total & $<0.001$ & 0.711 & 0.580 \\
\hline $\mathrm{pAR}^{\mathrm{S81}}$ cytoplasm & 0.166 & 0.578 & 0.057 \\
\hline $\mathrm{pAR}^{\mathrm{S81}}$ nucleus & 0.594 & 0.407 & 0.031 \\
\hline $\mathrm{pAR}^{\mathrm{S} 81}$ total & 0.925 & 0.383 & 0.039 \\
\hline $\mathrm{pAR}^{\mathrm{S94}}$ cytoplasm & 0.927 & 0.793 & 0.864 \\
\hline $\mathrm{pAR}^{\mathrm{S} 94}$ nucleus & 0.375 & 0.202 & 0.991 \\
\hline $\mathrm{pAR}^{\mathrm{S} 94}$ total & 0.178 & 0.425 & 0.884 \\
\hline pAR $^{\mathrm{S308}}$ cytoplasm & 0.255 & 0.423 & 0.423 \\
\hline $\mathrm{pAR}^{\mathrm{S} 308}$ nucleus & 0.974 & 0.634 & 0.628 \\
\hline $\mathrm{pAR}^{\mathrm{S} 308}$ total & 0.685 & 0.275 & 0.297 \\
\hline pAR $^{S 515}$ cytoplasm & 0.020 & 0.016 & $<0.001$ \\
\hline $\mathrm{pAR}^{\mathrm{S515}}$ nucleus & 0.877 & 0.189 & 0.072 \\
\hline $\mathrm{pAR}^{5515}$ total & 0.708 & 0.216 & 0.034 \\
\hline $\mathrm{pAR}^{\mathrm{S650}}$ cytoplasm & 0.977 & 0.431 & 0.113 \\
\hline $\mathrm{pAR}^{\mathrm{S} 650}$ nucleus & 0.909 & 0.229 & 0.177 \\
\hline $\mathrm{pAR}^{\mathrm{S650}}$ total & 0.530 & 0.342 & 0.059 \\
\hline Cdk1 cytoplasm & 0.988 & 0.011 & 0.007 \\
\hline Cdk1 nucleus & 0.791 & 0.624 & 0.434 \\
\hline Cdk1 total & 0.827 & 0.337 & 0.134 \\
\hline pCdk1 ${ }^{161}$ cytoplasm & 0.396 & 0.356 & 0.013 \\
\hline pCdk1 ${ }^{161}$ nucleus & 0.889 & 0.026 & 0.001 \\
\hline $\mathrm{pCdk} 1^{161}$ total & 0.166 & 0.413 & 0.007 \\
\hline pERK1/2 cytoplasm & 0.353 & 0.188 & 0.668 \\
\hline pERK1/2 nucleus & 0.384 & 0.207 & 0.509 \\
\hline pERK1/2 total & 0.525 & 0.487 & 0.973 \\
\hline \multicolumn{4}{|c|}{$\begin{array}{l}\text { Abbreviations: } \quad A R=\text { androgen receptor; } \quad C C=\text { Pearson's correlation coefficients; } \\
\text { PSA = prostate-specific antigen. } \\
\text { The proteins were grouped as } \leqslant \text { median or }>\text { median and analysed by Kaplan-Meier } \\
\text { methods with reference to clinical outcome measures as shown. } \\
\text { Patients were considered to have biochemical relapse dependent on treatment; radical } \\
\text { prostatectomy serum PSA }>0.2 \mathrm{ng} \mathrm{m}^{-1} \text {, radical radiotherapy serum PSA of } 2.0 \mathrm{ng} \mathrm{m}^{-1} \\
\text { above the post-treatment nadir level, hormone treatment } 2-3 \text { consecutive rises in serum } \\
\text { PSA levels above the nadir obtained at intervals of }>2 \text { weeks (Roach et al, 2006; Cookson } \\
\text { et al, 2007). } \\
\text { Numbers in bold denote significant associations with P-value }<0.05 \text {. }\end{array}$} \\
\hline
\end{tabular}

disease-specific survival $(P<0.001,10$-year survival $38.1 \%$ vs 100\%) (Figure 2B).

AR agonists stimulate Cdk1 and AR phosphorylation. In the clinical specimens, $\mathrm{pAR}^{\mathrm{S} 81}$ and $\mathrm{pAR}^{\mathrm{S} 515}$ were demonstrated to correlate with pCdk $1^{161}$. In vitro, it was observed by western blot analysis that the androgen DHT could induce phosphorylation of $\mathrm{Cdk}^{161}, \mathrm{AR}^{\mathrm{S} 81}$ and $\mathrm{AR}^{\mathrm{S} 515}$, with $\mathrm{AR}$ and $\mathrm{Cdk} 1$ expression levels remaining constant (Figure 3). Analysis of paraffin-embedded cell pellets confirmed the observation that treatment with DHT stimulates phosphorylation at $\mathrm{pCdk}^{161}, \mathrm{pAR}^{\mathrm{S} 81}$ and $\mathrm{pAR}^{\mathrm{S} 515}$ (Figure 4). As shown in Figure 4, it was demonstrated that DHT stimulated cellular proliferation, as assessed by Ki67. In addition, treatment with a Cdk inhibitor, Roscovitine, markedly decreased basal expression of $\mathrm{pCdk}^{161}, \mathrm{pAR}^{\mathrm{S} 81}, \mathrm{pAR}^{\mathrm{S} 515}$ and cell proliferation (Figure 4).

\section{DISCUSSION}

The current study suggests that in vitro activation of Cdk1 may be associated with phosphorylation of AR at Serine 81 and Serine 515, and thereby induce cellular proliferation. In addition, this association was also observed in the clinical specimens with $\mathrm{pAR}^{\mathrm{S} 515}$ expression observed to be a negative prognostic marker, independent of known clinical parameters.

Contrary to previous reports, pERK1/2 did not correlate with any of the AR phosphorylation sites predicted by Scansite (Anderson et al, 1990). In addition, pERK1/2 was not associated with any clinical outcome measures. We have previously reported that ERK1/2 is a negative prognostic marker in castrate-resistant prostate cancer; therefore, activation of the ERK1/2 pathway may be a late event and not associated with hormone-naive disease (Mukherjee et al, 2011). In support of this hypothesis, it was previously reported that ERK1/2 expression was low or undetectable in the majority of prostate cancer specimens at diagnosis, however increased with stage, Gleason grade and progression to castrate-resistant disease (Gioeli et al, 2006). In our patient cohort, phosphorylated ERK1/2 was not associated with Gleason grade and we postulate that disease progression may occur via other indirect mechanisms such as phosphorylation of the AR co-activator steroid receptor cofactor 1 , and increasing cellular proliferation through AP-1, c-MYC, and NF- $\mathrm{BB}$ (Bakin et al, 2003; Bell et al, 2003; Fu et al, 2003; Powell et al, 2004).

In the current study, we were surprised to observe that phosphorylated AR expression in the cytoplasm was a stronger prognostic factor than nuclear expression. However, presence of cytoplasmic AR is expected as the AR localises to the cytoplasm in the absence of ligand binding due to a ligand-regulated nuclear export signal (Tyagi et al, 2000; Wen et al, 2000). We suggest that immunohistochemical detection of cytoplasmic AR is an adverse prognostic feature as it may indicate high levels of nuclear receptor, as was the case with glucocorticoid receptors (McCarty et al, 1986). In support of this notion, AR expression and phosphorylation strongly correlated between the cytoplasm and nucleus in our study (results not shown) and high cytoplasmic $\mathrm{pAR}^{\mathrm{S} 515}$ expression was associated with worse clinical outcome. This is not the first study to observe that cytoplasmic AR expression is a stronger prognostic factor that nuclear expression, cytoplasmic AR expression in patients with negative surgical margins after radical prostatectomy was associated with worse prognosis (Diallo et al, 2008). Furthermore, the expression of cytoplasmic AR increased with the progression of prostate intraepithelial neoplasia to prostate cancer and from hormone-naive to castrate-resistant cancer (Diallo et al, 2008). In addition, the subcellular location and activity of AR is likely to be influenced by its phosphorylation status. We propose that differential phosphorylation of the AR as it shuttles between the nucleus and cytoplasm may be a more gradual process, allowing detection of phosphorylated residues in both cellular compartments by IHC. Alternatively, the kinases mediating AR phosphorylation at these residues may be dysregulated in malignant human prostate tissue, causing their localisation and activity not to be confined to a single compartment.

Notwithstanding these differences in the reported subcellular location of the $\mathrm{AR}$ and phosphorylated $\mathrm{AR}$, our results suggest that Cdk1 may phosphorylate multiple serine sites on the AR and demonstrate that they are of clinical significance in prostate cancer. In broad agreement with predictions by Scansite, phosphorylation of all putative Ser-Pro target sites on the AR correlated significantly with the expression of Cdk1 but not ERK1/2 in at least one cellular 

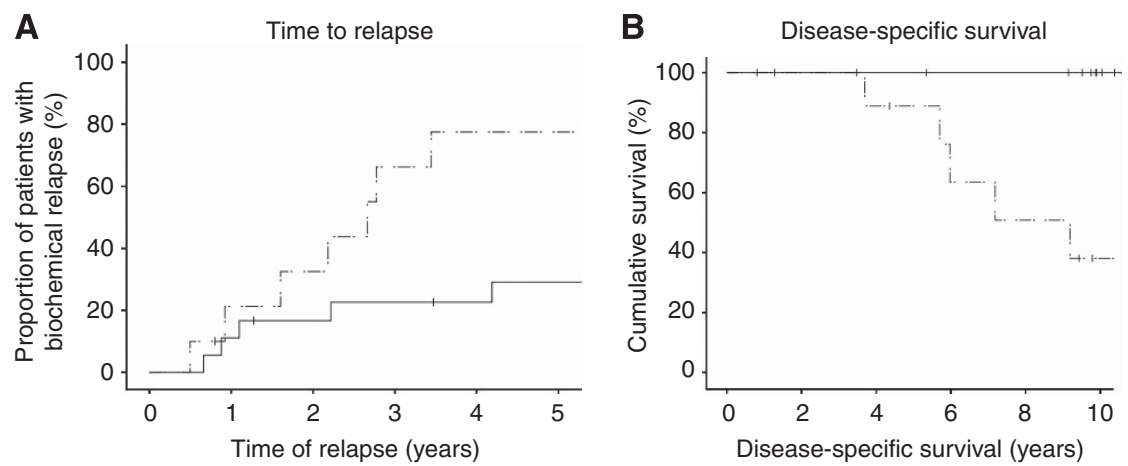

Figure 2. (A) Kaplan-Meier survival plot showing time to biochemical relapse in patients with PSA $\leqslant 20 \mathrm{ng} \mathrm{ml}^{-1}$ at diagnosis ( $n=28$ ) stratified according to low (solid line) and high (dashed line) cytoplasmic pAR $\mathrm{R}^{\mathrm{S} 15}$ expression. (B) Kaplan-Meier survival plot showing disease-specific survival in patients with PSA $\leqslant 20 \mathrm{ng} \mathrm{ml}^{-1}$ at diagnosis $(n=28)$ stratified according to low (solid line) and high (dashed line) cytoplasmic pAR ${ }^{5515}$

expression.

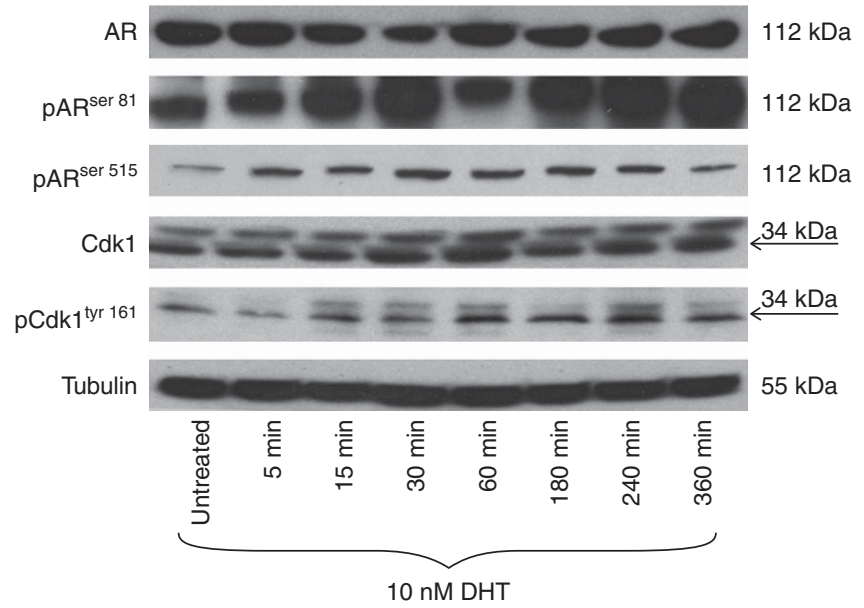

Figure 3. Western blot was performed on $50 \mu \mathrm{g}$ of extracts from LNCaP cells treated with $10 \mathrm{nM}$ dihydrotestosterone (DHT) for various lengths of time as shown. Cdk1 is known to have an isomer called CDC2deltaT that lacks 171 nucleotides corresponding to 57 amino acids, which compose most of the T-loop (Ohta et al, 1998). CDC2deltaT has been identified in breast cancer tissue, and currently there is no evidence for this in prostate cancer but it may account for the duplex band seen in Cdk1 and $\mathrm{pCdk} 1^{161}$.

location (Obenauer et al, 2003). Our study suggests that Cdk1 may drive phosphorylation of multiple serine sites on the AR. As Cdk1 expression correlated more strongly with certain phosphorylation sites, it may be that some sites are preferentially phosphorylated by related kinases, such as Cdk11 or Cdk7 (Zong et al, 2007; Chymkowitch et al, 2011). Not only did phosphorylation of the AR at predicted serine sites correlate with $\mathrm{Cdk} 1$ and $\mathrm{pCdk}^{161}$, both Cdk1 and $\mathrm{pCdk}^{161}$ were also strongly associated with clinical outcome measures. The association of Cdk1 expression in radical prostatectomy specimens with prostate cancer recurrence has been reported previously (Kallakury et al, 1997). Our study has added to this by observing that high expression of Cdk1, pCdk $1^{161}$ and phosphorylation of the putative Cdk1-consensus site $\mathrm{pAR}^{\mathrm{S515}}$ was associated with decreased survival from biochemical relapse and, in addition to $\mathrm{pAR}^{\mathrm{S} 81}$, disease-specific survival. These results suggest that phosphorylation of the AR by $\mathrm{Cdk} 1$ may be of functional importance.

Through the use of a Cdk inhibitor, we observed that $\mathrm{pAR}^{\mathrm{S} 81}$ and $\mathrm{pAR}^{\$ 515}$ expression is mediated, at least in part, by Cdk1. Previous work has suggested that increased Cdk1 activity is a mechanism for increasing AR expression, stability and cellular proliferation (Chen et al, 2006). In the current study although we observed an increase in Cdk1 phosphorylation AR expression remained stable, however, change in expression might take place over a longer time frame than investigated in the current study. We therefore consider that another role of Cdk1, out-with cell-cycle progression, is AR phosphorylation (in particular at serine 515). Thus, Cdk1 may provide a mechanism for accelerating disease progression in hormone-naive prostate cancer and a novel point for therapeutic intervention. Future work would consist of Cdk1 knockdown via cell silencing experiments to clarify the precise nature of the Cdk1/AR axis.

Ser-81 is the most frequently phosphorylated site on AR in response to androgen binding (Chen et al, 2006). However, $\mathrm{pAR}^{\mathrm{S} 515}$ was found to be independent of current clinical parameters ahead of $\mathrm{pAR}^{\mathrm{S} 81}$. This is in line with previous work which demonstrated that abolishment of $\mathrm{pAR}^{\mathrm{S} 81}$ in cell lines did not alter androgen-dependent AR transcriptional activity, rapidly induced AR-regulated genes or AR stabilisation mediated by Cdk1 (Chen et al, 2006). In contrast, similar removal of $\mathrm{pAR}^{\mathrm{S} 515}$ resulted in reduction of AR transcriptional activity in response to androgens (Ponguta et al, 2008). Our study provides additional evidence to support the hypothesis that site-specific AR phosphorylation is of clinical importance in prostate cancer.

The phosphorylated AR antibodies were stringently validated using western blot and peptide competition assays. We acknowledge the possibility of cross-reactivity in the usage of phosphospecific antibodies particularly on a protein such as AR with multiple phosphorylation sites. To follow on from the current study, we intend to validate these findings in a larger independent patient cohort. Before commencing these studies additional antibody validation will be performed via site-directed mutagenesis followed by IHC of cell pellets to establish with absolute certainty that the results observed are due to the individual phosphorylation sites.

An obvious limitation of this study is the small sample size and as such the results should be interpreted with caution and validated in a large independent cohort. However, even with low patient numbers, we have demonstrated that AR phosphorylation by Cdk1 at serine 515 can predict time to biochemical relapse in prostate cancer patients with PSA $\leqslant 20 \mathrm{ng} \mathrm{ml}^{-1}$. Within this group of patients, 10-year disease-specific survival was $100 \%$ in those patients with low $\mathrm{pAR}^{\mathrm{S} 515}$ expression compared with $38 \%$ in those with high expression. These results are striking in particular when considered that this was a hormone-naive cohort of patients who subsequently received a variety of treatments (surgery, radiotherapy and hormones) and that, due to small numbers, we were unable to unpick these groups. We now intend to pursue this work in a cohort of patients treated initially by active surveillance. 


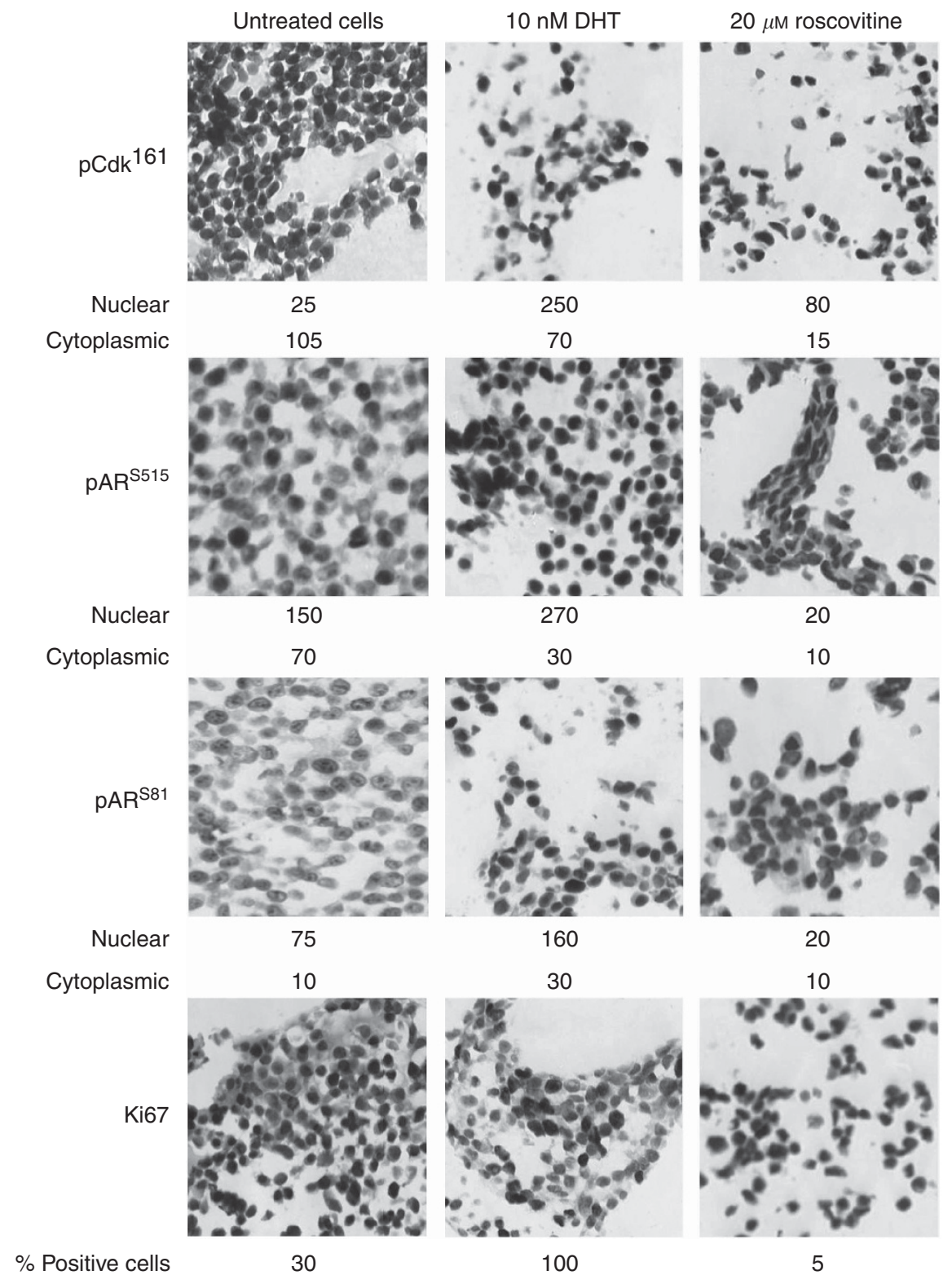

Figure 4. LNCaP cells were grown in full media and treated with either $10 \mathrm{nM}$ dihydrotestosterone (DHT) ( $3 \mathrm{~h})$ or $20 \mu \mathrm{M}$ Roscovitine (24h). Pellets were stained by immunohistochemistry for expression of $\mathrm{pCdk} 1^{161}, \mathrm{pAR}{ }^{\mathrm{S} 81}, \mathrm{pAR} \mathrm{R}^{\mathrm{S515}}$ and the nuclear marker of proliferation; Ki67. Weighted histoscores for cytoplasmic and nuclear expression are shown below each image for pCdk ${ }^{161}, \mathrm{pAR}^{\mathrm{S81}}$ and $\mathrm{pAR} \mathrm{R}^{\mathrm{S515}}$. Percentage of positive cells counted is shown below the images for Ki67.

This study suggests that Cdk1 may phosphorylate AR at serine 81 and serine 515, thereby driving cellular proliferation. In combination with current diagnostic tools, pAR ${ }^{5515}$ could provide a desperately needed prognostic marker to aid treatment decisionmaking in prostate cancer patients with PSA $\leqslant 20 \mathrm{ng} \mathrm{ml}^{-1}$ at diagnosis. This finding has the potential to reduce over-treatment of clinically insignificant disease and prevent delay in treatment of occult aggressive disease. Overall morbidity and mortality suffered by prostate cancer patients would be drastically reduced.

\section{ACKNOWLEDGEMENTS}

This study was supported by funding from the Association of International Cancer Research, Think Pink and NHS Greater Glasgow and Clyde Research Endowment Fund.

\section{REFERENCES}

Anderson NG, Maller JL, Tonks NK, Sturgill TW (1990) Requirement for integration of signals from two distinct phosphorylation pathways for activation of MAP kinase. Nature 343: 651-653.

Bakin RE, Gioeli D, Sikes RA, Bissonette EA, Weber MJ (2003) Constitutive activation of the Ras/mitogen-activated protein kinase signaling pathway promotes androgen hypersensitivity in LNCaP prostate cancer cells. Cancer Res 63: 1981-1989.

Bell WC, Myers RB, Hosein TO, Oelschlager DK, Grizzle WE (2003) The response of extracellular signal-regulated kinase (ERK) to androgeninduced proliferation in the androgen-sensitive prostate cancer cell line, LNCaP. Biotech Histochem 78: 11-16.

Blok LJ, de Ruiter PE, Brinkmann AO (1998) Forskolin-induced dephosphorylation of the androgen receptor impairs ligand binding. Biochemistry 37: 3850-3857. 
Chen S, Gulla S, Cai C, Balk SP (2012) Androgen receptor serine 81 phosphorylation mediates chromatin binding and transcriptional activation. J Biol Chem 287(11): 8571-8583.

Chen S, Xu Y, Yuan X, Bubley GJ, Balk SP (2006) Androgen receptor phosphorylation and stabilization in prostate cancer by cyclin-dependent kinase 1. Proc Nat Acad Sci USA 103: 15969-15974.

Chymkowitch P, Le May N, Charneau P, Compe E, Egly JM (2011) The phosphorylation of the androgen receptor by TFIIH directs the ubiquitin/ proteasome process. EMBO J 30(3): 468-479.

Cookson MS, Aus G, Burnett AL, Canby-Hagino ED, D'Amico AV, Dmochowski RR, Eton DT, Forman JD, Goldenberg SL, Hernandez J, Higano CS, Kraus SR, Moul JW, Tangen C, Thrasher JB, Thompson I (2007) Variation in the definition of biochemical recurrence in patients treated for localized prostate cancer: the American Urological Association Prostate Guidelines for Localized Prostate Cancer Update Panel report and recommendations for a standard in the reporting of surgical outcomes. J Urol 177: 540-545.

Diallo JS, Aldejmah A, Mouhim AF, Fahmy MA, Koumakpayi IH, Sircar K, Begin LR, Mes-Masson AM, Saad F (2008) Co-assessment of cytoplasmic and nuclear androgen receptor location in prostate specimens: potential implications for prostate cancer development and prognosis. BJU Int 101: 1302-1309.

Ferlay J, Shin HR, Bray F, Forman D, Mathers C, Parkin DM (2010) Estimates of worldwide burden of cancer in 2008: GLOBOCAN 2008. Int J Cancer 127: 2893-2917.

Fu Z, Smith PC, Zhang L, Rubin MA, Dunn RL, Yao Z, Keller ET (2003) Effects of raf kinase inhibitor protein expression on suppression of prostate cancer metastasis. J Natl Cancer Inst 95: 878-889.

Gioeli D, Black BE, Gordon V, Spencer A, Kesler CT, Eblen ST, Paschal BM, Weber MJ (2006) Stress kinase signaling regulates androgen receptor phosphorylation, transcription, and localization. Mol Endocrinol (Baltimore, MD) 20: 503-515.

Gioeli D, Paschal BM (2012) Post-translational modification of the androgen receptor. Mol Cell Endocrinol 352: 70-78.

Kallakury BV, Sheehan CE, Ambros RA, Fisher HA, Kaufman Jr RP, Ross JS (1997) The prognostic significance of p34cdc2 and cyclin D1 protein expression in prostate adenocarcinoma. Cancer 80: 753-763.

Kirkegaard T, Edwards J, Tovey S, McGlynn LM, Krishna SN, Mukherjee R, Tam L, Munro AF, Dunne B, Bartlett JM (2006) Observer variation in immunohistochemical analysis of protein expression, time for a change? Histopathology 48: 787-794.

Kuiper GG, Brinkmann AO (1995) Phosphotryptic peptide analysis of the human androgen receptor: detection of a hormone-induced phosphopeptide. Biochemistry 34: 1851-1857.

McCarty Jr. KS, Szabo E, Flowers JL, Cox EB, Leight GS, Miller L, Konrath J, Soper JT, Budwit DA, Creasman WT et al. (1986) Use of a monoclonal anti-estrogen receptor antibody in the immunohistochemical evaluation of human tumors. Cancer Res 46: 4244s-4248s.

Mistry M, Parkin DM, Ahmad AS, Sasieni P (2011) Cancer incidence in the United Kingdom: projections to the year 2030. Br J Cancer 105: 1795-1803.
Mukherjee R, McGuinness DH, McCall P, Underwood MA, Seywright M, Orange C, Edwards J (2011) Upregulation of MAPK pathway is associated with survival in castrate-resistant prostate cancer. Br J Cancer 104: 1920-1928.

Obenauer JC, Cantley LC, Yaffe MB (2003) Scansite 2.0: Proteome-wide prediction of cell signaling interactions using short sequence motifs. Nucleic Acids Res 31: 3635-3641.

Ohta T, Okamoto K, Isohashi F, Shibata K, Fukuda M, Yamaguchi S, Xiong Y (1998) T-loop deletion of CDC2 from breast cancer tissues eliminates binding to cyclin B1 and cyclin-dependent kinase inhibitor p21. Cancer Res 58: 1095-1098.

Ponguta LA, Gregory CW, French FS, Wilson EM (2008) Site-specific androgen receptor serine phosphorylation linked to epidermal growth factor-dependent growth of castration-recurrent prostate cancer. J Biol Chem 283: 20989-21001.

Powell SM, Christiaens V, Voulgaraki D, Waxman J, Claessens F, Bevan CL (2004) Mechanisms of androgen receptor signalling via steroid receptor coactivator-1 in prostate. Endocr Relat Cancer 11: 117-130.

Roach 3rd M, Hanks G, Thames Jr. H, Schellhammer P, Shipley WU, Sokol GH, Sandler H (2006) Defining biochemical failure following radiotherapy with or without hormonal therapy in men with clinically localized prostate cancer: recommendations of the RTOG-ASTRO Phoenix Consensus Conference. Int J Radiat Oncol Biol Phys 65: 965-974.

Shigemura K, Isotani S, Wang R, Fujisawa M, Gotoh A, Marshall FF, Zhau HE, Chung LW (2009) Soluble factors derived from stroma activated androgen receptor phosphorylation in human prostate LNCaP cells: roles of ERK/MAP kinase. Prostate 69: 949-955.

Tyagi RK, Lavrovsky Y, Ahn SC, Song CS, Chatterjee B, Roy AK (2000) Dynamics of intracellular movement and nucleocytoplasmic recycling of the ligand-activated androgen receptor in living cells. Mol Endocrinol (Baltimore, MD) 14: 1162-1174.

Wen Y, Hu MC, Makino K, Spohn B, Bartholomeusz G, Yan DH, Hung MC (2000) HER-2/neu promotes androgen-independent survival and growth of prostate cancer cells through the Akt pathway. Cancer Res 60: 6841-6845.

Wong HY, Burghoorn JA, Van Leeuwen M, De Ruiter PE, Schippers E, Blok LJ, Li KW, Dekker HL, De Jong L, Trapman J, Grootegoed JA, Brinkmann AO (2004) Phosphorylation of androgen receptor isoforms. Biochem J 383: 267-276.

Zhou ZX, Kemppainen JA, Wilson EM (1995) Identification of three prolinedirected phosphorylation sites in the human androgen receptor. Mol Endocrinol (Baltimore, MD 9: 605-615.

Zong H, Chi Y, Wang Y, Yang Y, Zhang L, Chen H, Jiang J, Li Z, Hong Y, Wang H, Yun X, Gu J (2007) Cyclin D3/CDK11p58 complex is involved in the repression of androgen receptor. Mol Cell Biol 27: 7125-7142.

This work is published under the standard license to publish agreement. After 12 months the work will become freely available and the license terms will switch to a Creative Commons AttributionNonCommercial-Share Alike 3.0 Unported License.

Supplementary Information accompanies this paper on British Journal of Cancer website (http://www.nature.com/bjc) 